\title{
COMMUNICATION IN MARKETING
}

\author{
R.Baki Deniz (Ph.D.) \\ (Marketing Researcher \\ Reporter / PaşabahçeTic.Ltd.Şti)
}

\section{I-) Communication and the Communication Process}

\section{A.Communication}

Communication can be said to happen whenever the individual attributes significance to message-related behavior (1).

Wilbur Schramm defined Communication as " the process of establishing a Commonness or oneness of thought between a sender and a receiver (2).

Central to this definition is the concept that for communication to occur there must be a transfer of information from one party-the Sender-which is received and understood by the other party-the receiver. In other words both receiver and Sender play an active role in establishing communication (3).

Communication, derived the Latin word communis, meaning common, is the process of establishing commonness (4).

\section{B. The Communication Process}

The nature of communication is best illustrated by an analysis of the communication process between two persons. Mass communication is not different in its essential nature (5).

Communication is a process linking a source and a receiver (6). The process of communication has three essential elements a source, a message, and a destination. Transmittal of the message requires a channel (7). 
According to Rosenberg: (8)

The communication process consists of six basic elements:

•communicator:the sender or the source of the message; message-the

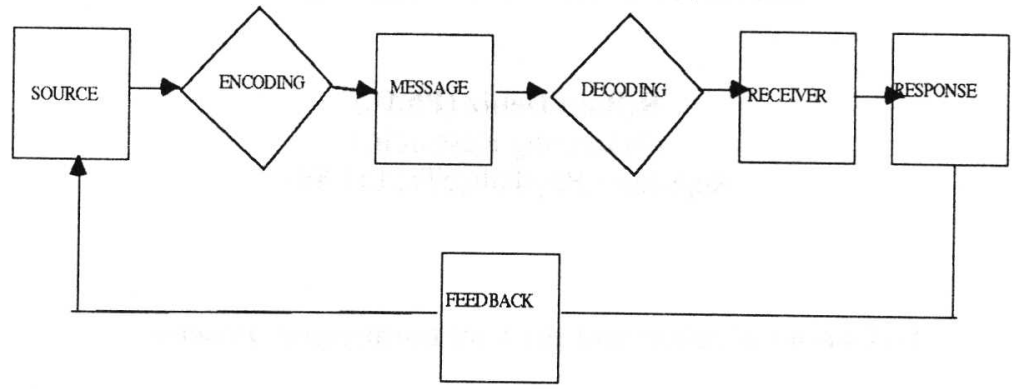

set of meaninings being sent and/or received by the audience,

-channels:the ways in which messages can be carried or delivered to the audience,

-audience:the receiver or the destination

-noise:conditions that distort the communication process

The communication process is visualized in Figure 1.

\section{II-)The marketing Communication and the Marketing Commu nication Process}

\section{A. The Marketing Communication}

Marketing communication is the process by which messages are developed by the marketer and transmitted to intended receivers (the target market audience). effectiveness is measured by how well the messages are received, understood and acted upon (9).

The source of the message is the sender.

The organization must decide what it wants to communicite, to whom 
and for what purpose. Encoding is the use of symbols to communicate the message. Symbols may be words, pictures sounds, animation, or mood setting.

The channel is the medium used to deliver the message, for example, television, radio magazin or newspaper.

Decoding is how the receiver perceives the symbols and interprets the message. Few messages are understood as precisely or a completely as the sender would like.

Response is how the receiver reacts to the message. The response can vary from a change in awareness to outright purchase.

Feedback is the transmittal of performance measurement back to the source. This information may come from sales records, marketing research or the sales force (10).

The marketing communication involves three types of organizations: the marketing organization, advertising agencies, and media. The marketing organization-that is, the manufacturer, of the brand being advertised-is responsible for developing the product, positioning it, and paying for the communications process. The company's advertising agency develops a compaign to inform and influence consumers. It also develops an overall communications mix composed not only of advertising, but of direct mail, in store displays, sales promotions and public relations. In addition, the agency develops a media plan that might involve $\mathrm{Tv}$, radio, magazine and newspaper ads. The media are responsible for running the ads developed by the agency (11).

\section{B. The Marketing Communication Process}

A modern company manages a complex marketing-communication system. The company communicates with its middlemen, consumers, and various publics. Consumers have word-of-mouth communication with each other and with other publics. Meanwhile each group provides feedback to every other group (12).

According to Kotler; " A company's total marketing communications program-called its promotion mix-consists of the specific blend of advertising, sales promotion, public relations and personal selling that the company used to pursue its advertising and marketing objectives (13). 


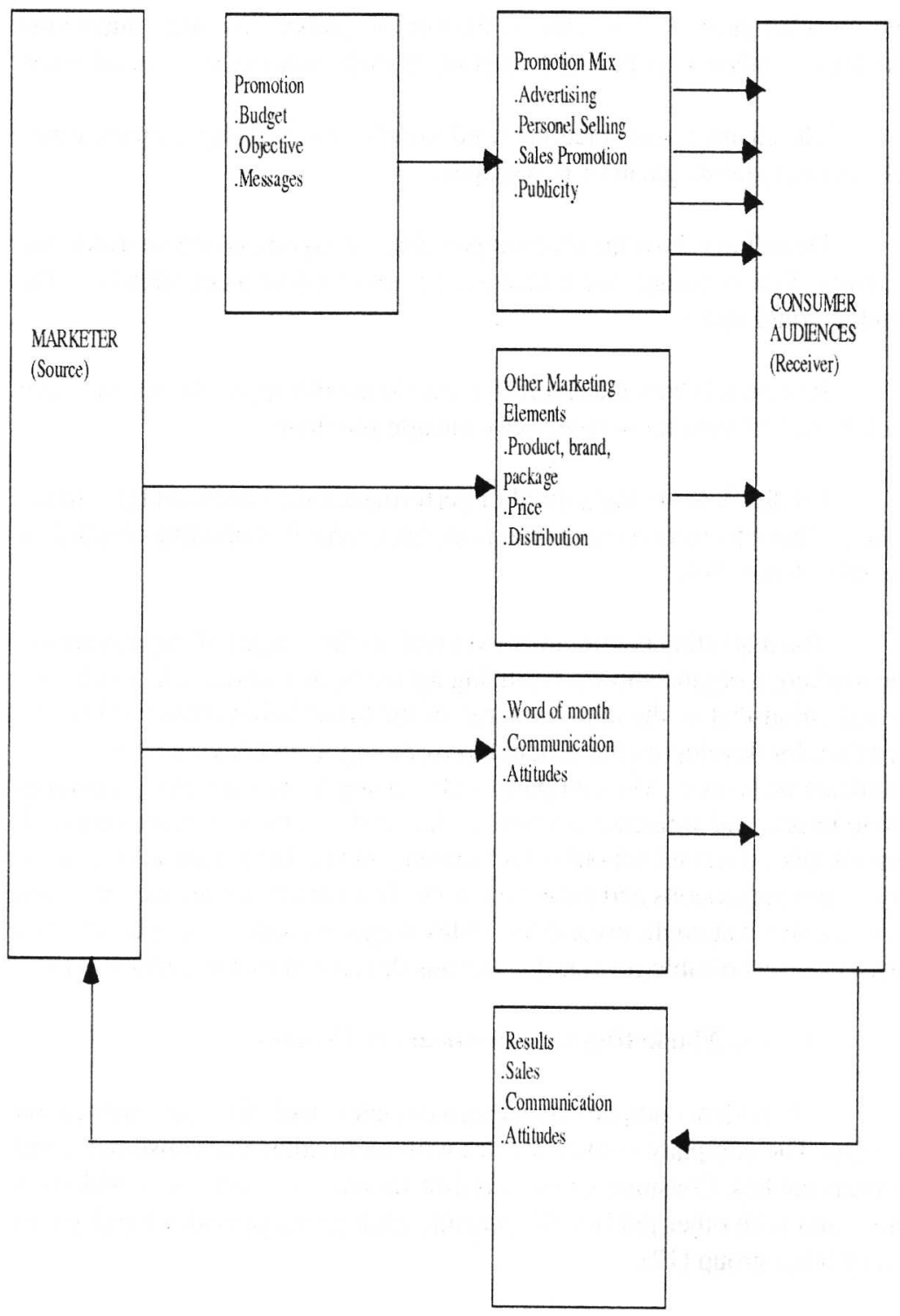

With the communication process outlined above in mind, let's examine how promotion functions as communication tool within the marketing strategy context. 
Figure 2 presents a marketing communication model. As the model indicates, there are varions ways in which marketers communicate with consumers. The controllable communications channels include the promotion mix and other marketing elements.

Let's take a closer look at the key variables in the model in figure 2(14).

-Audience:The first role of mass communications is to "know your audince' This means refining the specific groups that you will address, and determining the relevant needs and goals of the target market.

As Philip Kotler stated that: "The communicator must start with the audience because the audience determines what is to be said. how it is to be said, when it is to be said, where is to be said, and who is to say it (15).

- Objectives, promotion is must likely to be succesfull when a firm begins with clear, realistic and carefully researched objectives.

-Messages: There are two fundamental decision in message strategy: what is to be said and how it is to be said. All messages must be formulated with the product's market position in mind.

-Communication channels: There are four principal communications channels available to the marketing manager: media (television, radio, newspapers, direct mail), face to face (sales people), publicity (new releases), and word-of-mouth (among consumers). All marketing elements communicate with buyers in one way or another. A marketer often uses more than one channel of communication at the same time. since the two channels may reinforce each other's influence.

-Source: A marketing message can come from the company manufactiring the product, the retailer who sells the product, the sales people or announcers in commercials, and/or the media as a whole. Receivers may not be willing even to "receive" a message if it comes from a disliked source.

- Results: Marketers face a number of critical problems in evaluating the results of various promotional efforts. Most feedback on mass media promotion comes weeks or even months afterwards. This makes marketing analysis even more difficult (16). 


\section{III-) Design of a Communication Strategy}

Development of a proper communication strategy involves as a thought process as well as an implementation procedure. The following steps outline a design of a communication strategy, working backward from the ultimate objective (17).

-Objective setting: To define goals and determine desired responses and/or transactions.

-Market definition: To determine one or more market segments; that is, message destinations.

-Segments: that is, message destinations.

-Experimentation: Throught Aesting, to gather date on how alternative messages will be deoded and responded to.

-Message creation: To develop offers and other elements of the message that are likely to achieve the desired response.

-Media selection: To search and define those media that can most efficiently and effectively deliver the intended messages to the target market segments.

Image building: To create a reputation or favorable attitude toward the organization as a source of communication on products and services.

-Feedback: To measure and evaluate response to communication as an aid to designing subsequent strategies.

\section{REFERENCES}

(1) C. David Mortensen, Communication, the Study of Human Interaction , Mc Graw-Hill Book Co. New York 1972, p.14.

(2) Michael J.Baker, Marketing, An Introductory Text The Mc Millan Press Ltd. London 1980, p.255.

(3) Michael J. Baker, 1980, p.255.

(4) Martin Baier, Elements of Direct Marketing Mc Graw-Hill Inc.New York, 1985, p.283. 
(5) James F.Engel, Martin R.Warshaw, Thomas C.Kinnear, Prometional Strategy, Managing the Marketing Communication Process, Richard D.Irwin Inc.Illinois, 1979, p.20.

(6) David, W.Crawens, Strategic Marketing, Richard D.Irwin Inc. U.S.A. 1987, p.499.

(7) Martin Baier, Elements of Direct Marketing Mc Graw-Hill Inc.New York, 1985, p.283.

(8) Larry, J.Rosenberg, Marketing Prentice-Hall Inc. New-Jersey, 1977, p.403.

(9) Victor P.Buell, Marketing Management, A Strategic Planning Apporoach, Mc Graw Hill Series in Marketing U.S.A. 1985, p.583.

(10) Victor P.Buell, 1985, p.584.

(11) Henry Assael, Marketing, Principles and Strategy The Dryden Press Orlando, 1990, p.13.

(12) Philip Kotler, Garry Armstrong, Principles of Marketing , Prentice Hall Inc. New Jersey 1984, p.422.

(13) Philip Kotler, Garry Armstrong, 1984, p.422.

(14) Larry, J.Rosenberg, 1977, p.405-406.

(15) Philip Kotler, Marketing Management, Analysis, Planning and Control, Prentice Hall Inc. New Jersey 1991, p.325.

(16) Larry, J.Rosenberg, 1977, p.406.

(17) Martin Baier.1985, p.285. 